\title{
ATP7B expression confers multidrug resistance through drug sequestration
}

\author{
F M Moinuddin ${ }^{1,2}$, Yoshinari Shinsato ${ }^{2,3}$, Masaharu Komatsu ${ }^{4}$, Ryoichi Mitsuo ${ }^{2, *}$, \\ Kentaro Minami 2,3, Masatatsu Yamamoto ${ }^{2,3}$, Kohich Kawahara2,3, Hirofumi Hirano ${ }^{1}$, \\ Kazunori Arita ${ }^{1}$, Tatsuhiko Furukawa ${ }^{2,3}$ \\ ${ }^{1}$ Department of Neurosurgery, Kagoshima University Graduate School of Medical and Dental Sciences, 8-35-1 Sakuragaoka, \\ Kagoshima 890-8544, Japan \\ ${ }^{2}$ Department of Molecular Oncology, Kagoshima University Graduate School of Medical and Dental Sciences, 8-35-1 \\ Sakuragaoka, Kagoshima 890-8544, Japan \\ ${ }^{3}$ Center for the Research of Advanced Diagnosis and Therapy of Cancer, Graduate School of Medical and Dental Sciences, \\ Kagoshima University, 8-35-1 Sakuragaoka, Kagoshima 890-8544, Japan \\ ${ }^{4}$ Division of Food and Chemical Biology, Faculty of Fisheries, Kagoshima University, 4-50-20, Shimoarata, Kagoshima \\ 890-0056, Japan \\ "Present address: Shin Nippon Biomedical Laboratories (SNBL) Ltd, 2438 Miyanoura, Kagoshima 891-1394, Japan \\ Correspondence to: Tatsuhiko Furukawa, e-mail: furukawa@m3.kufm.kagoshima-u.ac.jp \\ Keywords: ATP7B, copper transporter, multidrug resistance, doxorubicin, SN-38 \\ Received: November 10,2015 Accepted: February 23, $2016 \quad$ Published: March 14, 2016
}

\section{ABSTRACT}

We previously reported that ATP7B is involved in cisplatin resistance and ATP7A confers multidrug resistance (MDR) in cancer cells.

In this study, we show that ATP7B expressing cells also are resistant to doxorubicin, SN-38, etoposide, and paclitaxel as well as cisplatin.

In ATP7B expressing cells, doxorubicin relocated from the nuclei to the lateendosome at 4 hours after doxorubicin exposure. EGFP-ATP7B mainly colocalized with doxorubicin.

ATP7B has six metal binding sites (MBSs) in the $\mathrm{N}$-terminal cytoplasmic region. To investigate the role of the MBSs of ATP7B in doxorubicin resistance, we used three mutant ATP7B (Cu0, Cu6 and M6C/S) expressing cells. Cu0 has no MBSs, Cu6 has only the sixth MBS and M6C/S carries CXXC to SXXS mutation in the sixth MBS. Cu6 expressing cells were less resistance to the anticancer agents than wild type ATP7B expressing cells, and had doxorubicin sequestration in the late-endosome. CuO- and $\mathrm{M6C} / \mathrm{S}$-expressing cells were sensitive to doxorubicin. In these cells, doxorubicin did not relocalize to the late-endosome. EGFP-M6C/S mainly localized to the trans-Golgi network (TGN) even in the presence of copper. Thus the cysteine residues in the sixth MBS of ATP7B are essential for MDR phenotype.

Finally, we found that ammonium chloride and tamoxifen suppressed late endosomal sequestration of doxorubicin, thereby attenuating drug resistance. These results suggest that the sequestration depends on the acidity of the vesicles partly.

We here demonstrate that ATP7B confers MDR by facilitating nuclear drug efflux and late endosomal drug sequestration.

\section{INTRODUCTION}

ATP7A and ATP7B are copper transporters existing in the Golgi membrane and share $67 \%$ amino acid identity. They have six metal binding sites (MBS) in the N-terminal cytoplasmic region and 8 membrane spanning segments. They have important roles in the copper homeostasis in animal cells [1-3]. Several mutations of ATP7A and ATP7B are causes of Menkes and Wilson disease respectively [4].

In the other hand, we previously found that high expression of ATP7B confers resistance against cisplatin and this has since been confirmed by other groups [5-7]. ATP7B expression has been reported as a poor 
Table 1: Chemosensitivity of wt and mutant ATP7B-expressing cells

\begin{tabular}{|c|c|c|c|c|c|c|c|c|c|}
\hline Cells & $\mathrm{KB} / \mathrm{EV}$ & KB/WD & & $\mathrm{KB} / \mathrm{Cu}$ & & $\mathrm{KB} / \mathrm{Cu}$ & & $\mathrm{KB} / \mathrm{M} 6 \mathrm{C} /$ & \\
\hline Agent & $\mathrm{IC}_{50}$ & $\mathrm{IC}_{50}$ & $\mathbf{R R}$ & $\mathrm{IC}_{50}$ & $\mathbf{R} \mathbf{R}$ & $\mathrm{IC}_{50}$ & $\mathbf{R R}$ & $\mathrm{IC}_{50}$ & RR \\
\hline cisplatin $(\mu \mathrm{M})$ & $1.52 \pm 0.02$ & $18.27 \pm 1.15$ & $12.03^{\mathrm{I}}$ & $5.00 \pm 0.24$ & $3.30^{ \pm}$ & $1.71 \pm 0.20$ & 1.13 & $1.71 \pm 0.12$ & 1.12 \\
\hline doxorubicin $(\mu \mathrm{M})$ & $0.25 \pm 0.02$ & $4.27 \pm 0.53$ & $17.25^{\mathrm{I}}$ & $1.84 \pm 0.19$ & $7.43^{\mathrm{I}}$ & $0.29 \pm 0.08$ & 1.16 & $0.23 \pm 0.04$ & 0.95 \\
\hline SN-38 (nM) & $17.65 \pm 0.60$ & $673.07 \pm 23.59$ & $38.14^{\mathrm{f}}$ & $101.32 \pm 3.56$ & $5.74^{\mathrm{I}}$ & $23.53 \pm 1.94$ & $1.33^{\mathrm{f}}$ & $24.83 \pm 0.44$ & $1.40^{\mathrm{I}}$ \\
\hline etoposide $(\mu \mathrm{M})$ & $5.22 \pm 0.94$ & $134.77 \pm 6.73$ & $25.84^{\mathrm{I}}$ & $113.27 \pm 1.55$ & $21.72^{\mathrm{f}}$ & $5.71 \pm 0.37$ & 1.10 & $6.25 \pm 0.02$ & 1.20 \\
\hline paclitaxel (nM) & $10.45 \pm 1.60$ & $20.93 \pm 1.44$ & $2.00^{\mathrm{f}}$ & $14.18 \pm 1.23$ & $1.35^{\mathrm{I}}$ & $8.67 \pm 0.20$ & 0.83 & $11.57 \pm 0.43$ & 1.10 \\
\hline
\end{tabular}

$\mathrm{IC}_{50}$ values are means \pm SDs from triplicate determinations with MTT assay.

$\mathrm{RR}$ (relative resistance) is a value that $\mathrm{IC}_{50}$ for $\mathrm{KBWD}, \mathrm{MCu} 6, \mathrm{MCu} 0$, or $\mathrm{M} 6 \mathrm{c} / \mathrm{s}$ divided with $\mathrm{IC}_{50}$ for $\mathrm{KB} / \mathrm{EV}$ cells,

respectively.

I Indicates statistically significant $(p<0.05)$

prognostic marker in some cancers receiving cisplatinbase chemotherapy $[8,9]$. ATP7A also has been reported to confer cisplatin resistance [10].

Additionally we indicated that ATP7A expressing cells are resistant against not only cisplatin but also a variety of anticancer agents including doxorubicin, $\mathrm{SN}$ 38 , etoposide, vincristine and paclitaxel through vesicle transport dependent ways. Surgically resected ATP7A positive human colon tumor cells were significantly resistant to SN-38 than ATP7A negative cells ex vivo [11]. That means ATP7A confers multidrug resistance (MDR) of cancer cells and related to drug resistance in clinical cancer cells.

MDR is a characteristic that the cells are resistant to multiple structurally unrelated anticancer agents and an obstacle for successful cancer chemotherapy. MDR is caused by expression of some $\mathrm{ABC}$ transporters, modification of DNA repair systems, apoptosis defects and several more mechanisms $[12,13]$. However there are no established therapies to overcome MDR in practice so far $[14,15]$.

Here we evaluated drug sensitivities of ATP7B expressing cells to make clear that ATP7B also confers MDR and examined the mechanism of ATP7B mediated drug resistance with mutant ATP7B expressing cells and imaging of doxorubicin localization.

\section{RESULTS}

\section{Resistance to anticancer agents of ATP7B expressing cells}

We previously reported that ATP7A confers resistance against a wide variety of anticancer agents in addition to cisplatin [11]. We first examined whether wt ATP7B expressing KB/WD cells are resistant to anticancer agents other than cisplatin by 3-(4, 5-dimethylthiazol-2yl)-2, 5-diphenyltetrazolium bromide (MTT) assay. We found that $\mathrm{KB} / \mathrm{WD}$ cells are significantly resistant to doxorubicin (17.25fold), SN-38 (38.14 fold), etoposide (25.84 fold), and paclitaxel (2.00 fold) as well as cisplatin (12.03fold) in comparison with $\mathrm{KB} / \mathrm{EV}$, pRC/CMV plasmid transfected KB-3-1 cells (Table 1).

\section{Doxorubicin localizes to the late endosome in ATP7B-expressing cells}

Doxorubicin has an intrinsic red fluorescence that allows observation of its localization. We observed the intracellular distribution of doxorubicin at 0 time and at 4 hours after doxorubicin treatment and washing with PBS with confocal laser fluorescence microscopy. In KB/ EV cells, doxorubicin was localized predominantly to the nuclei at both time points (Figure 1a, 1b). Alternatively, in $\mathrm{KB} / \mathrm{WD}$ cells, doxorubicin was localized in the nuclei at 0 time but after 4 hours, was predominantly localized in the cytoplasm (Figure 1c, 1d).

To determine the cytoplasmic localization of doxorubicin in ATP7B expressing cells, we observed doxorubicin distribution in the Green Fluorescence Protein (GFP)-Golgi or GFP-late endosome transfected cells in the presence of bathocuproine disulphonate (BCS), a copper chelate, at 4 hours after doxorubicin exposure. Doxorubicin in KB/WD cells predominantly co-localized with GFP-late endosomes and not with GFP-Golgi (Figure 2). Therefore, doxorubicin is sequestrated into the late endosome compartment from the nuclei in ATP7B expressing cells independent of copper.

\section{ATP7B localizes to the late endosome in the presence of doxorubicin}

Not only copper but also cisplatin causes the relocalization of ATP7B from the trans-Golgi network (TGN) to the peripheral vesicles $[6,16]$. We examined the localization of ATP7B after exposure of doxorubicin using EGFP-wt ATP7B transfection to KB-3-1 cells. When BCS is used to deplete copper, EGFP-ATP7B mainly 
colocalized with RFP-Golgi (Supplementary Figure 1a and 1b). By contrast in the presence of copper, EGFP-ATP7B localizes to the late endosome (Supplementary Figure $1 \mathrm{c}$ and $1 \mathrm{~d})$. These results are consistent with that copper levels influence the localization of ATP7B and result in its change from the TGN to the late endosome as previously reported $[17,18]$.

Next, we examined the effect of doxorubicin on ATP7B localization in EGFP-ATP7B transiently transfected KB-3-1 cells in the presence of BCS. The ATP7B colocalized with doxorubicin in the late endosome at 4 hours after doxorubicin treatment (Figure 3a). Therefore, doxorubicin, copper, and cisplatin alter the ATP7B subcellular localization from the TGN to the late endosome $[6,16]$. These results suggest that ATP7B can be activated with a metal unrelated chemical agent.

\section{The sixth metal binding site of ATP7B is critical for doxorubicin resistance and relocalization of ATP7B}

In previous reports, the cytoplasmic MBSs, especially the cysteine residues in the sixth MBS (MBS6) of ATP7B are/is essential for copper transport and cisplatin resistance $[16,19]$. We examined whether the MBSs in ATP7B are important for doxorubicin sequestration and resistance.

Figure $4 \mathrm{a}$ presents a schematic drawing of the $\mathrm{N}$-terminus of ATP7B proteins used in this study as described in the material and method. $\mathrm{Cu} 0$ has no $\mathrm{MBSs}$, $\mathrm{Cu} 6$ has only the sixth $\mathrm{MBS}$ and $\mathrm{M} 6 \mathrm{C} / \mathrm{S}$ carries $\mathrm{CXXC}$ to SXXS mutation in the sixth MBS. Cu0, Cu6 and M6C/S expressing $\mathrm{KB}-3-1$ cells are named $\mathrm{KB} / \mathrm{Cu} 0, \mathrm{~KB} / \mathrm{Cu} 6$ and $\mathrm{KB} / \mathrm{M} 6 \mathrm{C} / \mathrm{S}$ respectively.
The protein expression of wild type (wt) and mutant ATP7B was examined by immunoblotting using anti-HA antibody (Figure 1b). The expression of each ATP7B protein was comparable in each cell line. Full-length wt ATP7B and M6C/S (170 kDa) and the ATP7B deletion mutants, $\mathrm{Cu} 0$ and $\mathrm{Cu} 6$, were detected at their expected sizes $120 \mathrm{kDa}$ and $125 \mathrm{kDa}$ respectively (Figure 4b).

In MTT assay, $\mathrm{KB} / \mathrm{Cu} 0$ cells were sensitive to the agents, suggesting that the cytoplasmic MBSs are important for resistance to doxorubicin and other anticancer agents. $\mathrm{KB} / \mathrm{Cu} 6$ cells were more resistant to cisplatin (3.30-fold), doxorubicin (7.4-fold), SN-38 (5.7fold), etoposide (21.7-fold), and paclitaxel (1.35-fold) than $\mathrm{KB} / \mathrm{EV}$ cells, but less resistant than KB/WD wt ATP7Bexpressing cells. $\mathrm{KB} / \mathrm{M} 6 \mathrm{C} / \mathrm{S}$ cells were sensitive to these agents (Table 1). These results suggest that MBS6 of ATP7B is critical for doxorubicin resistance while MBSs 1-5 increase resistance but are not required.

To identify where doxorubicin localizes in these mutant ATP7B expressing cells, we observed doxorubicin localization after transfection with GFP-late endosome. In $\mathrm{KB} / \mathrm{Cu} 6$ cells, which have some drug resistance, doxorubicin was detected in both the cytoplasm and nuclei at 4 hours after exposure and was partly co-localized with the GFP-late endosome like KB/WD (Figure 5c). In $\mathrm{KB} / \mathrm{M} 6 \mathrm{C} / \mathrm{S}$ and $\mathrm{KB} / \mathrm{Cu} 0$ cells, doxorubicin was mainly localized in the nuclei (Figure $5 \mathrm{a}, 5 \mathrm{~b}$ ). Furthermore in EGFP-M6C/S expressing KB-3-1 cells, doxorubicin localized to the nuclei and EGFP-M6C/S protein localized to cytoplasm differently from those in the EFGP-ATP7B expressing cells (Figure 3).

Therefore, the cysteine residues of MBS6 are essential for ATP7B mediated drug sequestration in the late endosome. These results support that the sequestration of
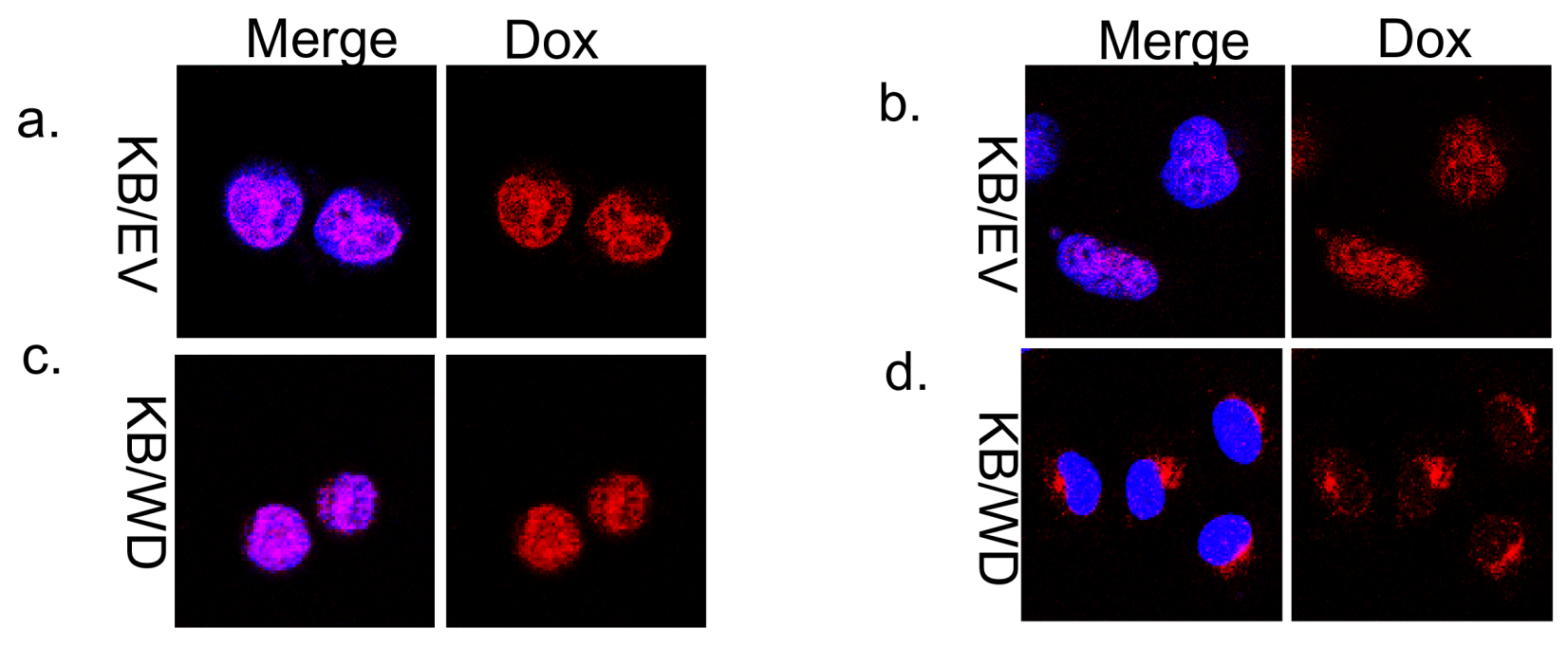

Figure 1: Doxorubicin localization in $\mathrm{KB} / \mathbf{E V}$ and $\mathrm{KB} / \mathrm{WD}$ cells. Cells were exposed to doxorubicin for 1 hour and washed with PBS. Localization was observed in KB/EV cells at 0 time a and b. at 4 hours after washing PBS. Localization was observed in KB/WD cells c. at 0 time and d. 4 hours after washing PBS. Doxorubicin is red. The nuclei are stained with Hoechst 33342 (blue). 
a.
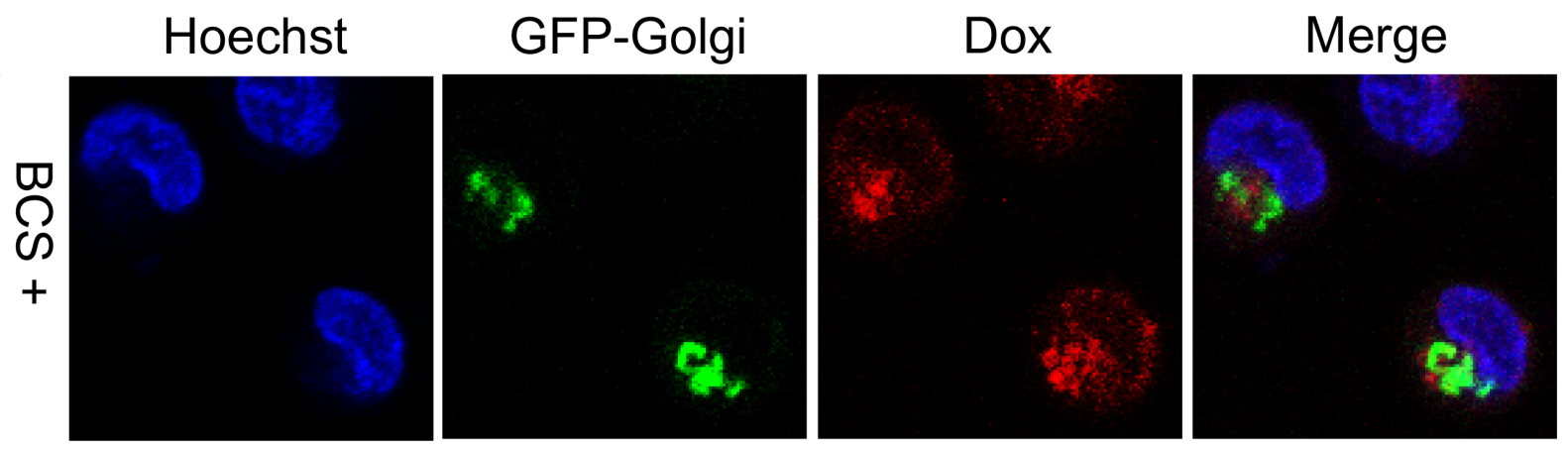

b.

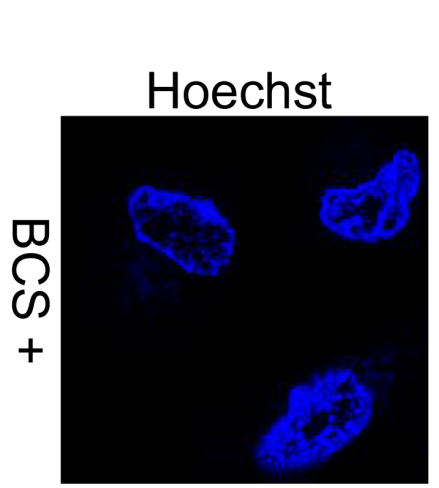

\section{GFP.} late endosome

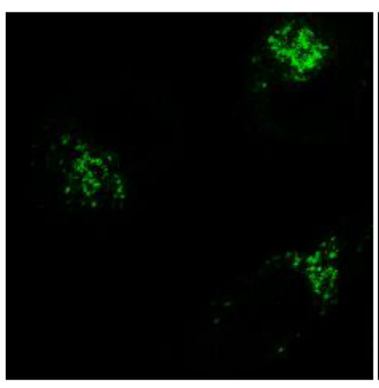

Dox

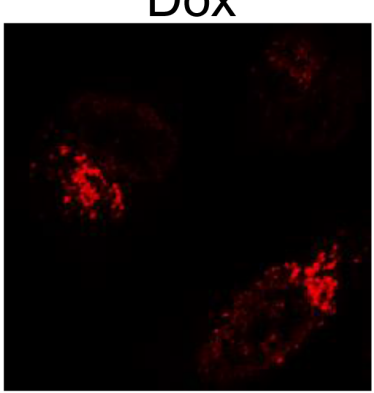

Merge

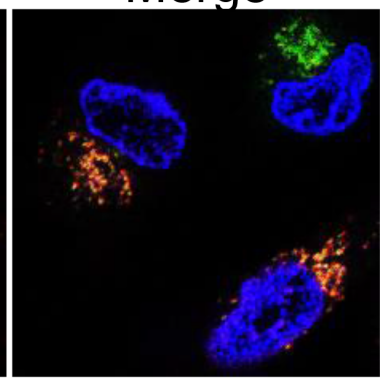

Figure 2: Subcellular localization of doxorubicin in KB/WD cells. Subcellular localization of doxorubicin at 4 hours after its exposure and washing with PBS in a. GFP-Golgi (green) transfected KB/WD cells and b. GFP-late endosome (green) transfected KB/WD cells. Doxorubicin is red. The nuclei are stained with Hoechst 33342 (blue).

a.

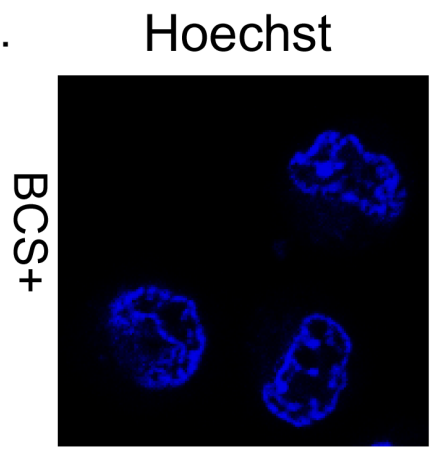

b.

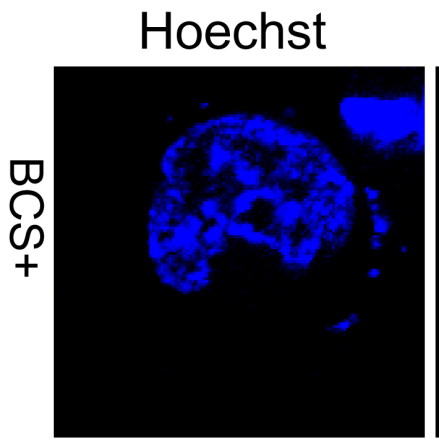

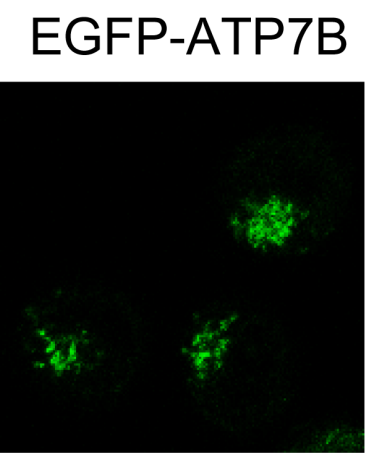
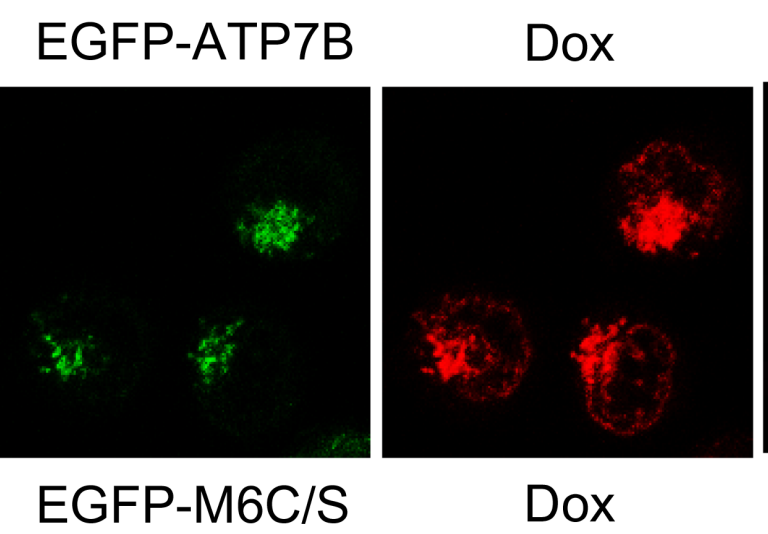

Dox
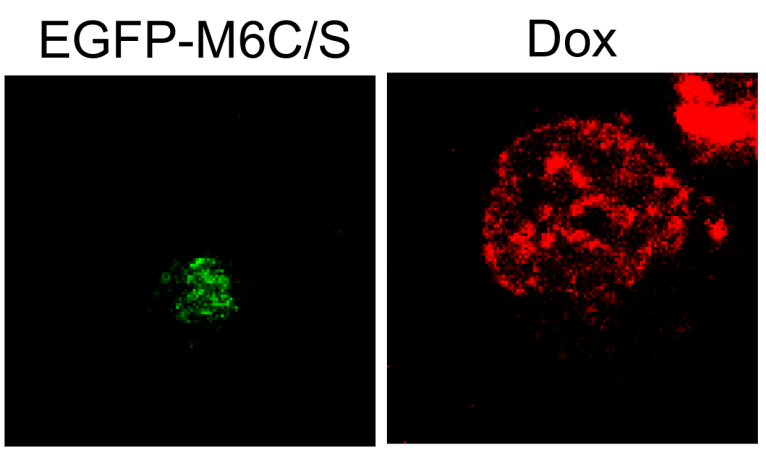

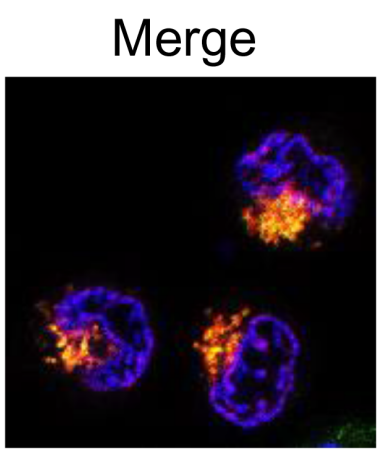

Merge

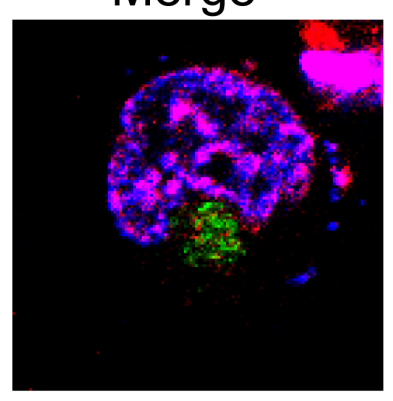

Figure 3: Subcellular localization of doxorubicin and EGFP-ATP7B or EGFP-M6C/S. Subcellular localization of doxorubicin and ATP7B and M6C/S at 4 hours after doxorubicin exposure and washing with PBS in EGFP-ATP7B (green) a. or EGFP-M6C/S (green) b. transfected KB-3-1 cells. Doxorubicin is red. The nuclei are stained with Hoechst 33342 (blue). 
(a)
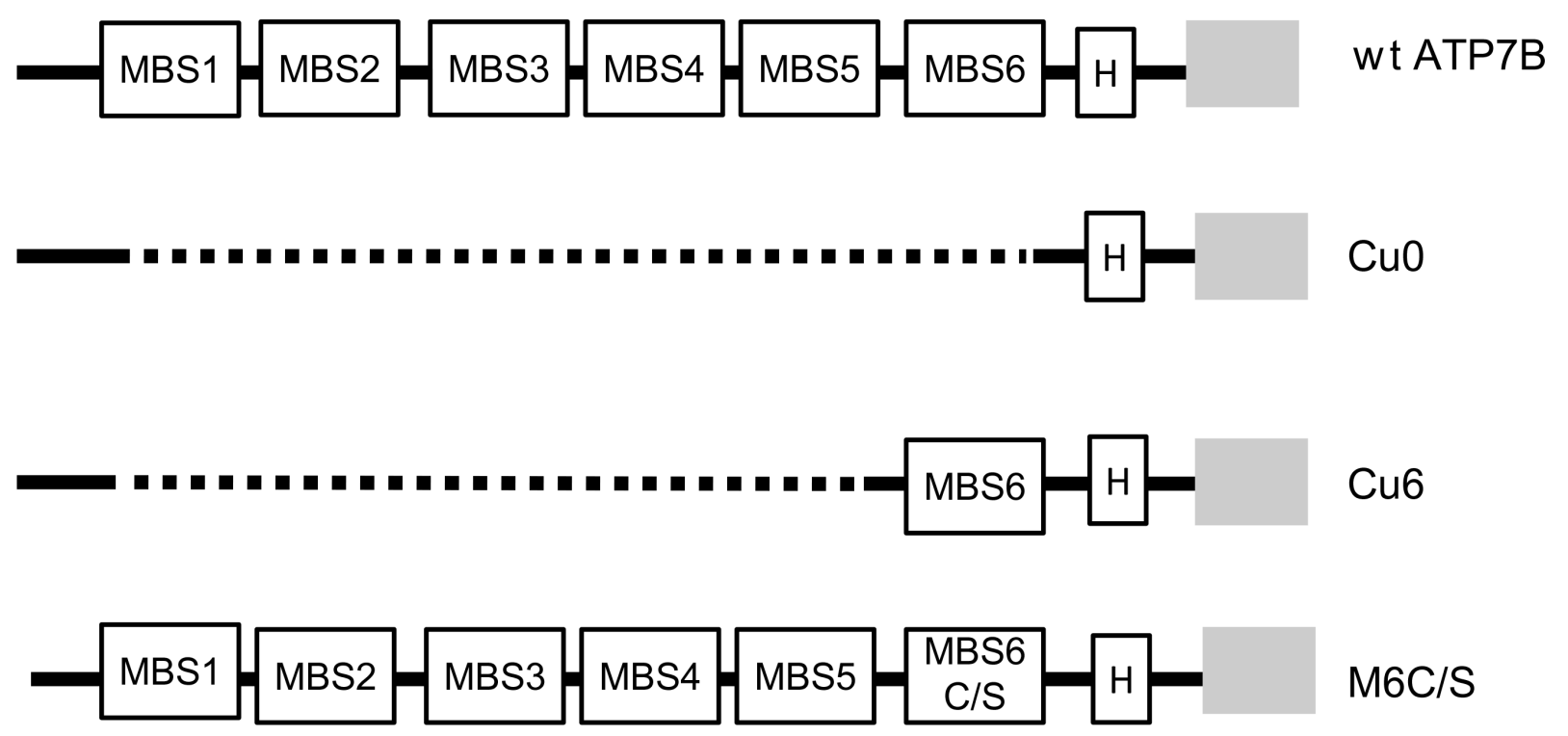

(b)

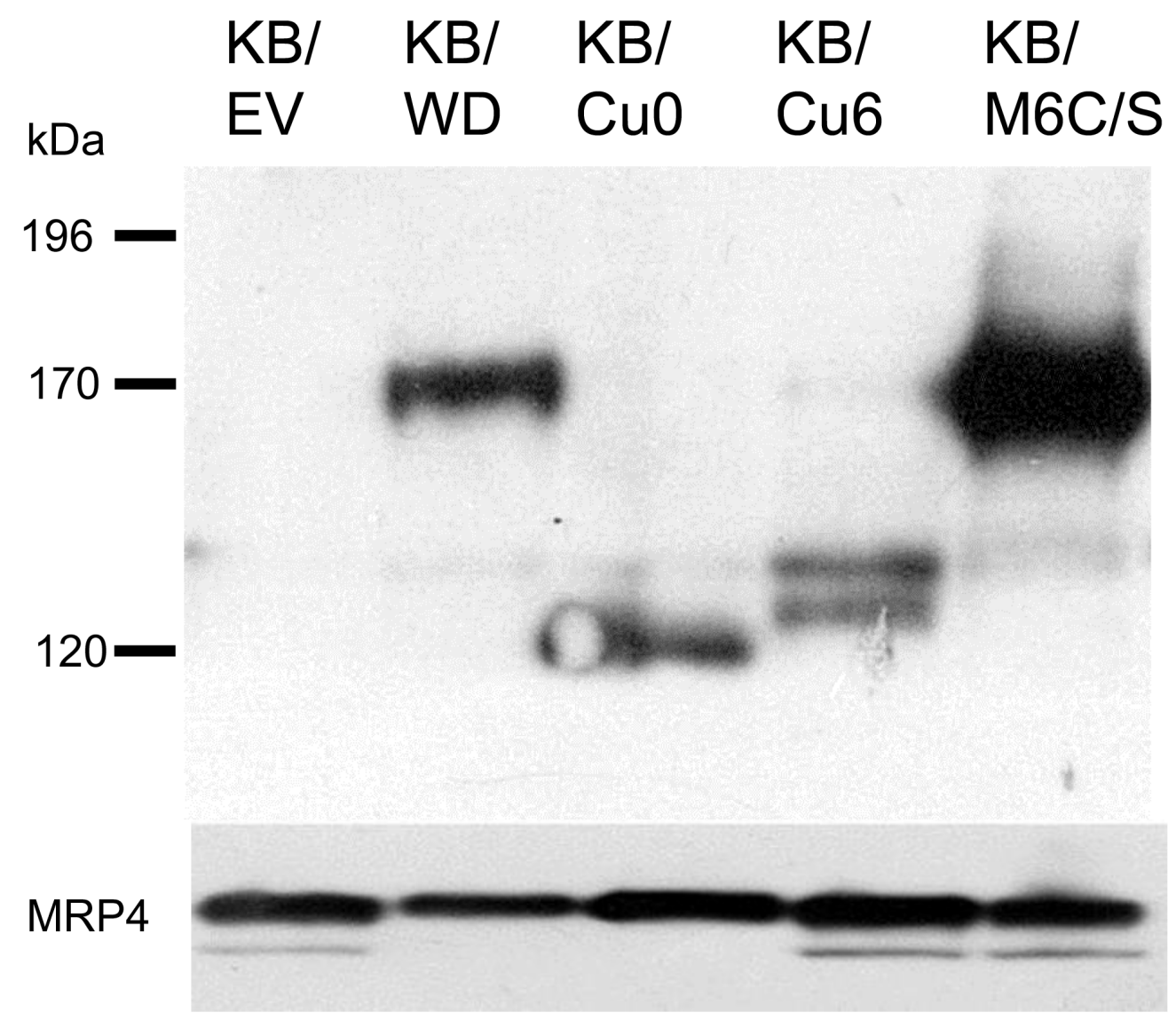

Figure 4: a. Schematic presentation of the N-terminal part of wt and mutant ATP7B proteins used in this study. Open boxes indicate MBSs, grey boxes indicate the transmembrane domain, black lines indicate protein, and grey dotted lines indicate deletions. H means HA epitope. MBS6C/S indicates that CXXC in the 6th MBS has been converted to SXXS. b. Expression of the wt and mutant ATP7B proteins from the indicated cells lysate detected by immunoblotting. ABCC4/MRP4 protein was indicated as loading control of membrane fraction protein. 
doxorubicin is mediated by ATP7B through its interaction with doxorubicin via MBS6.

\section{Acidic condition in the vesicles contribute to doxorubicin sequestration}

To investigate whether doxorubicin sequestration in the late endosome depends on the acidity of the vesicles, we examined doxorubicin localization in the presence of $\mathrm{NH}_{4} \mathrm{Cl}$ or tamoxifen. $\mathrm{NH}_{4} \mathrm{Cl}$ is a lysosomotropic agent that inhibits sequestration of weakly basic molecules in the vesicle by increasing the endo-lysosomal $\mathrm{pH}$. Tamoxifen inhibits acidification of endosomes and lysosomes without increasing cytoplasmic $\mathrm{pH}[20,21]$. In the presence of $\mathrm{NH}_{4} \mathrm{Cl}$ or tamoxifen, doxorubicin accumulated in the nuclei and only slightly colocalized with the GFP-late endosome (Figure 6). Next, we estimated whether $\mathrm{NH}_{4} \mathrm{Cl}$ or tamoxifen could modify cell viability. The viability of doxorubicin treated KB/WD cells significantly decreased in the presence of both $\mathrm{NH}_{4} \mathrm{Cl}$ and tamoxifen, although there was no remarkable change in that of $\mathrm{KB} / \mathrm{EV}$ cells. Preventing sequestration of drugs in the acidic vesicle by $\mathrm{NH}_{4} \mathrm{Cl}$ could increase the sensitivity of $\mathrm{KB} / \mathrm{WD}$ cells against doxorubicin and SN-38 (Figure 7).

In addition to $\mathrm{NH}_{4} \mathrm{Cl}$, tamoxifen can reduce ATP7B mediated drug resistance to doxorubicin, cisplatin, and SN-38. However, the effects of cisplatin are weaker than those of doxorubicin. This result is consistent with doxorubicin being a weak base (pKa 9.53/8.94 strongest acidic and strongest basic respectively), which allows it to accumulate in the acidic vesicles, while cisplatin (pKa 5.06) and SN-38 (pKa 9.68/3.91 strongest acidic and strongest basic respectively) are more acidic and acidification has weaker effect to accumulation of these compounds. These results indicate that ATP7B mediated doxorubicin sequestration partially depends on the acidity of the vesicles.

\section{DISCUSSION}

We previously reported that expression of either ATP7B confers cisplatin resistance and that the expression of ATP7A confers resistance to several

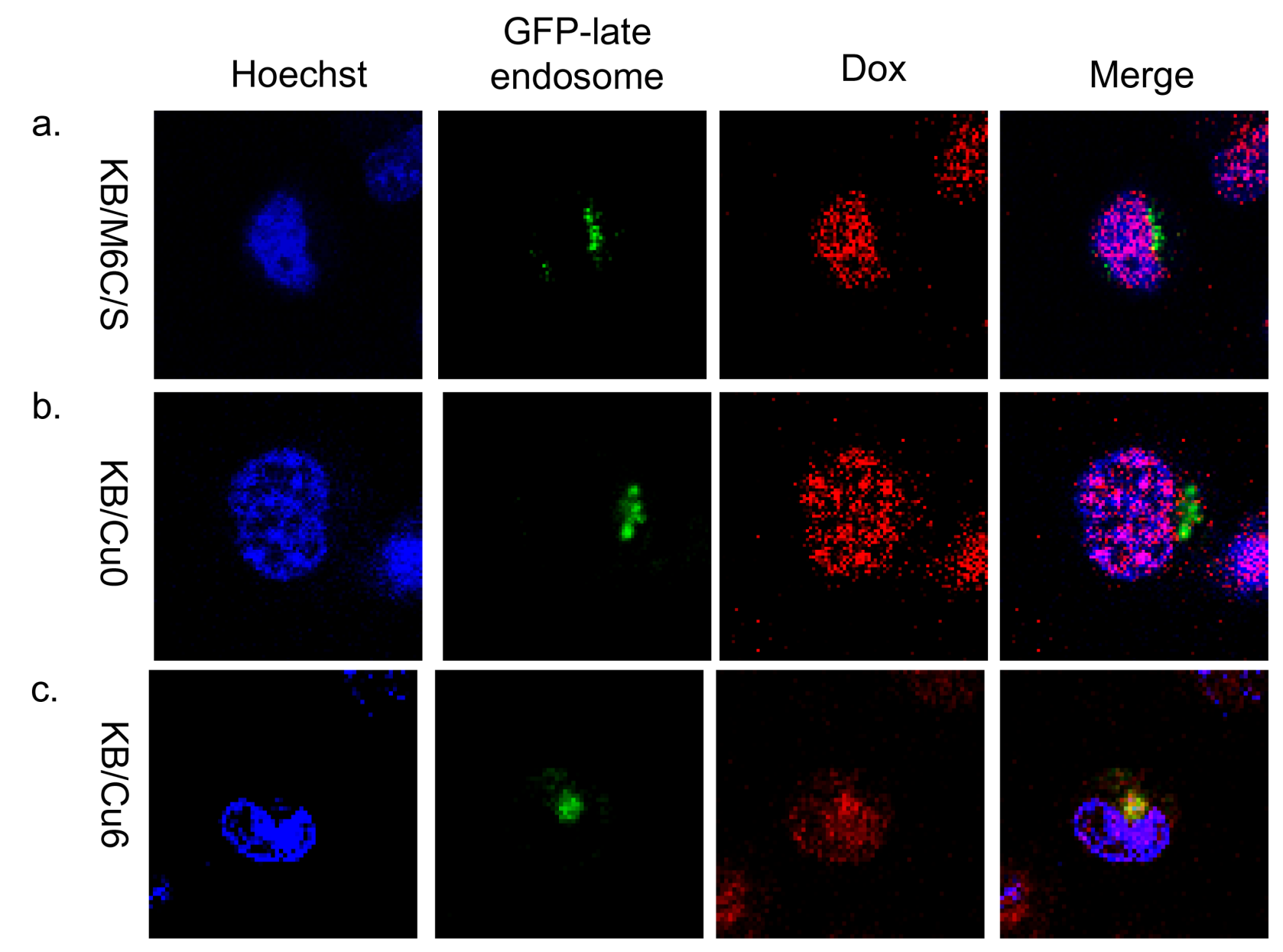

Figure 5: Subcellular localization of doxorubicin in mutant ATP7B expressing cells. Subcellular localization of doxorubicin at 4 hours after doxorubicin exposure and washing with $\mathrm{PBS}$ in $\mathbf{a} . \mathrm{KB} / \mathrm{M} 6 \mathrm{C} / \mathrm{S}, \mathbf{b}$. KB/Cu0, and c. KB/Cu6 cells. GFP-late endosomes are green, doxorubicin is red. The nuclei are stained with Hoechst 33342 (blue). 
structurally unrelated anticancer drugs including cisplatin $[5,11]$. The involvement of ATP7B in resistance to other anticancer drugs has not been investigated. Here we show that ATP7B confers resistance to doxorubicin, SN-38, etoposide, and paclitaxel, making ATP7B another candidate of MDR.

ATP7B normally resides in the TGN of hepatocytes. In the presence of elevated copper levels, ATP7B is redistributed from the TGN to the late endosome/lysosome compartments [17, 18]. Tagged wt ATP7B localizes to the TGN under both copper- and cisplatin-free conditions and is dispersed throughout the cell after 1 hour of exposure to either cisplatin or copper $[6,16]$. Fluorescein-labeled cisplatin localizes to the TGN and lysosome and colocalizes with both ATP7B and ATP7A $[6,22]$. Here we show that exposure to doxorubicin also induces redistribution of ATP7B to the late endosome, similar to exposure to copper and cisplatin. Additionally, we show ATP7B facilitates efflux from the nuclei and sequestration of doxorubicin to the late-endosome. Taken together, these results suggest that
ATP7B is activated by doxorubicin as well as by copper and cisplatin.

The CXXC motif in MBS6 of ATP7B is essential for the transport of $\mathrm{Cu}$ and for trafficking in response to cisplatin $[16,23,24] . \mathrm{KB} / \mathrm{M} 6 \mathrm{C} / \mathrm{S}$ cells are sensitive to cisplatin, doxorubicin, $\mathrm{SN}-38$, etoposide and paclitaxel suggesting that the CXXC motif of MBS6 is important for resistance to these anticancer agents. Alternatively, $\mathrm{KB} / \mathrm{Cu} 6$ cells are resistance to these agents, but are less resistant than KB/WD cells to them. The resistance of the mutant-expressing cells to doxorubicin is correlated with the amount of doxorubicin accumulation in the late endosome based on our confocal microscopic study (Figure 4 and 5). Thus, MBS6 is critical to drug resistance; however, MBS6 alone is not sufficient to confer resistance comparable to wt ATP7B. MBSs 1-5 have supportive roles in the function of ATP7B.

Our results are compatible with previous studies investigating the MBSs of ATP7B. The second MBS in the N-terminal domain of ATP7B is important in receiving copper from Atox1, a cytosolic copper chaperone [25]. Platinum can also transfer copper to

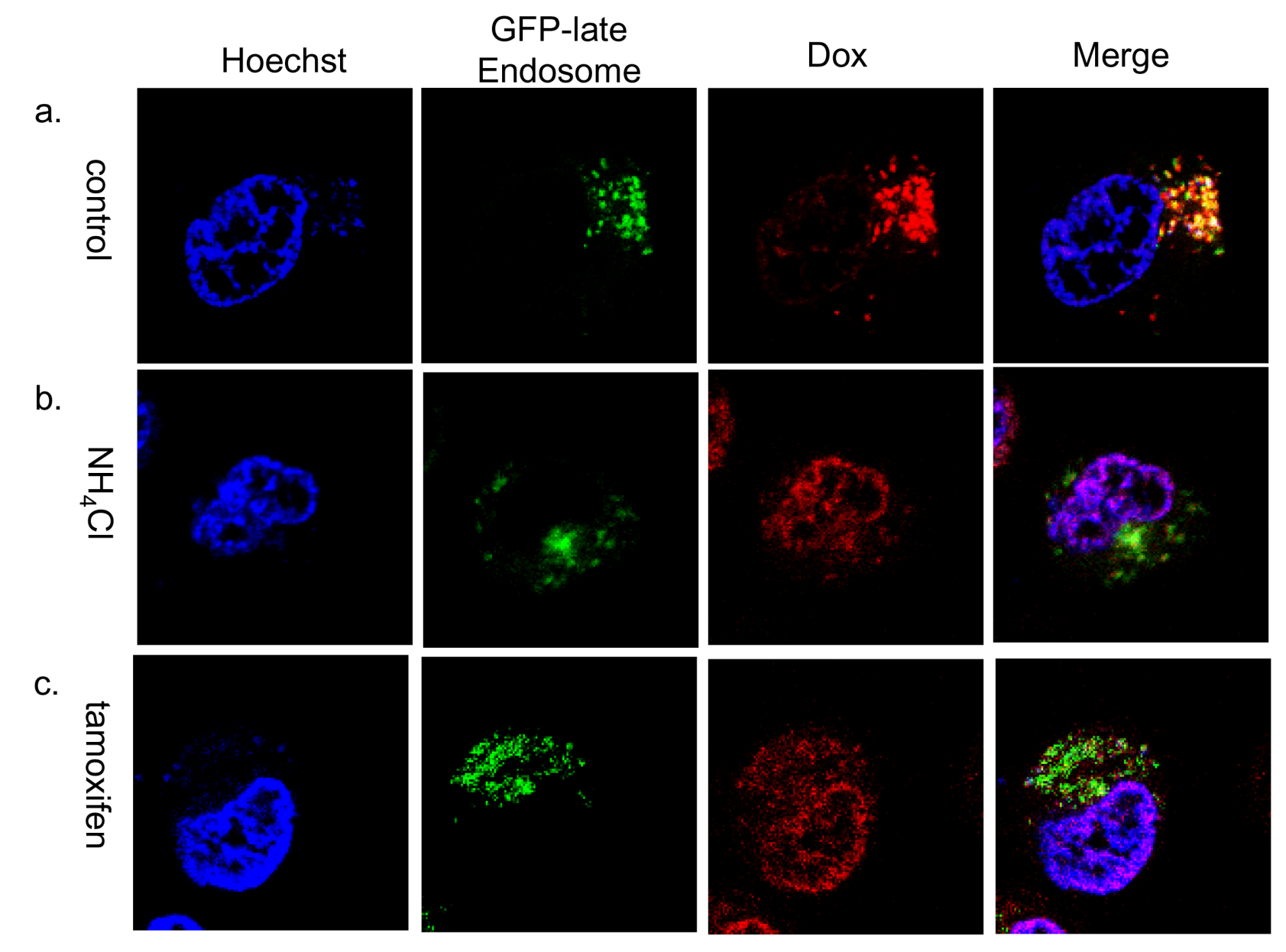

Figure 6: Subcellular localization of doxorubicin in $\mathrm{NH}_{4} \mathrm{Cl}$ or tamoxifen treated KB/WD cells. Subcellular localization of doxorubicin in a. GFP-late endosome (green) transfected KB/WD cells at 4 hours after exposure, $\mathbf{b}$. in the presence of $10 \mathrm{mM} \mathrm{NH}_{4} \mathrm{Cl}$, or c. in the presence of $10 \mu \mathrm{M}$ tamoxifen. Doxorubicin is red. The nuclei are stained with Hoechst 33342 (blue). 
the second MBS from Atox1 [26]. The fragment of $\mathrm{N}$-terminal ATP7B including MBSs 1-4 binds with the copper-bound Atox1 in the yeast two hybrid system [27]. Cisplatin also binds to MBSs 1-4 but not MBSs 5 or 6 of ATP7B based on studies using proteins expressed in Escherichia coli [28]. Therefore, MBSs 1-4 might have higher affinity to the copper than MBS6. These reports are consistent with MBSs 1-4 having a supportive function of ATP7B transport activity. MBSs $1-5$ is expected to also interact with doxorubicin since $\mathrm{KB} / \mathrm{Cu} 6$ cells are less resistant to anticancer agents in comparison with $\mathrm{KB} / \mathrm{WD}$ cells.

Cisplatin was shown to be transported by the ATP7B-expressing vesicle using the baculovirus expressing system [24]. Recently, electrical measurements using a membrane fraction of ATP7A- or ATP7Bexpressing Cos- 1 cells demonstrated a charge transfer in the presence of cisplatin, indicating an ATP-dependent vectorial displacement of a charged cisplatin complex by ATP7A and ATP7B [29]. We previously showed that SN-38 could be transported into the membrane vesicles

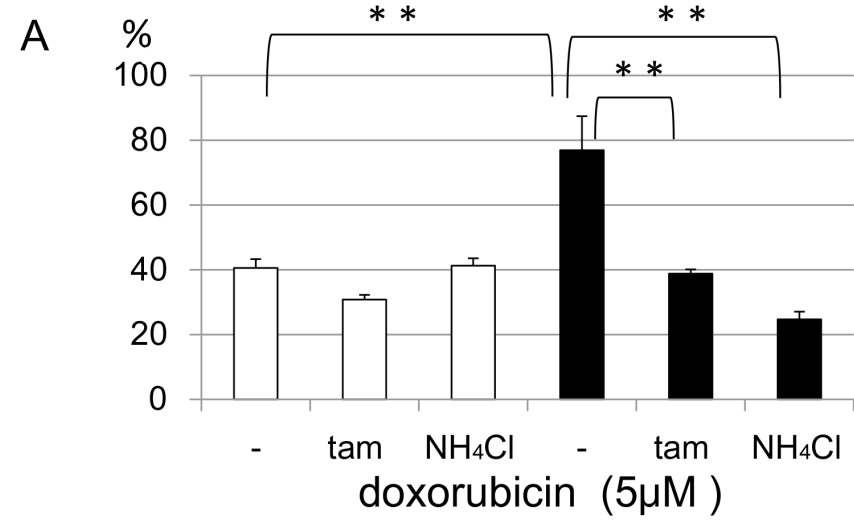

C

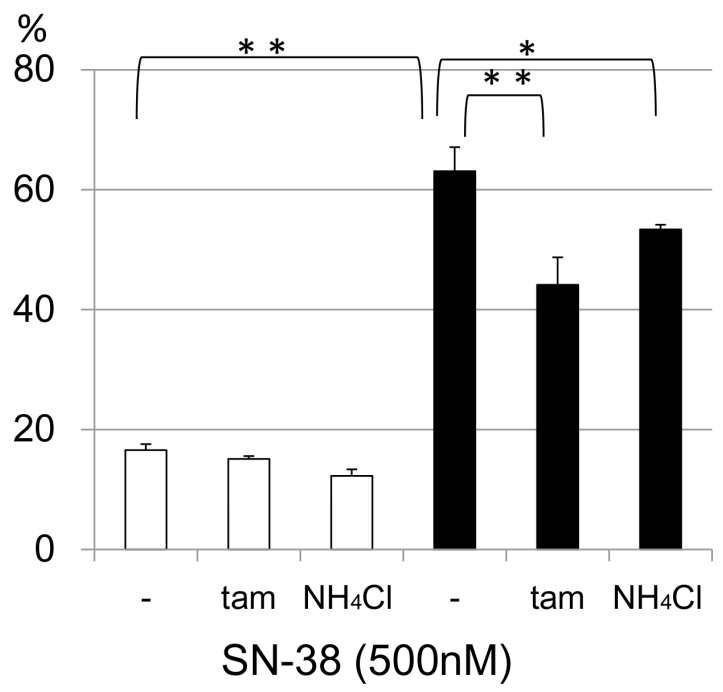

of ATP7A-expressing cells [11]. These results suggest ATP7A and ATP7B directly transfer cisplatin or SN-38 to acidic vesicles.

Since many chemotherapeutic agents, which target molecules including nucleic acids, topoisomerases, and DNA polymerase, localize to the nucleus, alteration of the intracellular distribution of these chemicals strongly influences their efficacy [30-32]. Vesicle acidification has been proposed to play one of major roles in drug sequestration [33]. Previously, we found that in ATP7A-expressing cells, monensin, which disturbs the acidity of the vesicles, could relocate doxorubicin from intracellular vesicles to the nuclei [11]. In our present study, the inhibition of vesicle acidification with $\mathrm{NH}_{4} \mathrm{Cl}$ or tamoxifen altered drug distribution and significantly reversed the cell viability in ATP7B expressing cells. Thus, ATP7B confers resistance through late endosomal sequestration, which partly depends on acidification.

In this study indicates that ATP7B potentially facilitate doxorubicin efflux from the nuclei and following

$\mathrm{B}$

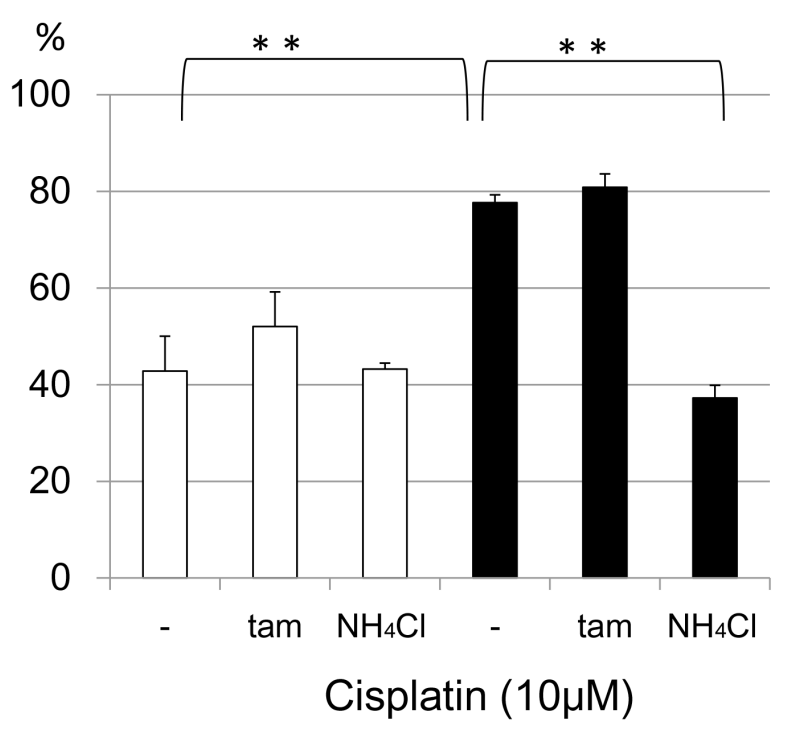

Figure 7: Effects of $\mathrm{NH}_{4} \mathrm{Cl}$ or tamoxifen (tam) on $\mathrm{KB} / \mathrm{EV}$ and $\mathrm{KB} / \mathrm{WD}$ cell viability in the presence of anticancer agents. In the presence of a. $5 \mu \mathrm{M}$ doxorubicin, b. $10 \mu \mathrm{M}$ cisplatin, or c. $500 \mathrm{nM} \mathrm{SN}-38$, the effect of $10 \mathrm{mM} \mathrm{NH}_{4} \mathrm{Cl}$ or $10 \mu \mathrm{M}$ tamoxifen on cell viabilities of $\mathrm{KB} / \mathrm{EV}$ cells (open bar) and $\mathrm{KB} / \mathrm{WD}$ cells (black bars) are indicated. Data represent means of triplicate determination. ${ }^{*} P$ $<0.05, * * \mathrm{P}<0.001)$ 
late endo-lysosomal drug sequestration, and confers drug resistance to cancer cells. More detailed analysis of the mechanism of drugs sequestration is required.

Appearance of drug resistant, especially MDR, cells hinders successful chemotherapy treatments. Several mechanisms of MDR, including expression of some $\mathrm{ABC}$ transporters, increase detoxification, DNA repair and apoptosis defects have been reported $[12,13]$. The therapy against MDR is not established, one of the reason is not all mechanisms of MDR have not been elucidated [14]. It has been reported that ATP7B expression elevate in several human malignancies, including ovarian, gastric, and breast cancers when compared with non-cancer tissues and its high expression is a poor prognostic marker in ovarian and oral squamous cell cancers treated with cisplatin-base chemotherapy [8, 34-36]. Using PrognoScan (http://www.abren.net/PrognoScan/) we found that high ATP7B expression is a poor prognosis index in several neoplasms which non-platina base chemotherapy are applied as standard protocol for: AML (data set GSE8970: P<0.014613), DLBCL (data set E-TABM-346: $\mathrm{p}<0.026222$ ), follicular lymphoma (data set GSE16131-GPL97: $\mathrm{p}<0.040192$ ), glioma (data set GSE4412-GPL97: P<0.005900).

According to our analysis and previous reports, ATP7B is expected to be important position in MDR of human cancers clinically as well as cisplatin resistance. In this study, we show that ATP7B confers MDR to cancer cells, similarly to ATP7A, by facilitating nuclear efflux and following late endosome drug sequestration.

\section{MATERIALS AND METHODS}

\section{Chemicals}

We purchased G-418, cisplatin, doxorubicin etoposide, paclitaxel and tamoxifen form Sigma Chemical Co., (St, Louis, MO), Glutamine, $\mathrm{NH}_{4} \mathrm{Cl}$ and $\mathrm{CuCl}_{2}$ from Wako (Osaka, Japan), and HEPES and BCS from Dojindo (Kumamoto, Japan). SN-38 was obtained by donation (Daiichi Sankyo Pharmaceutical Co. Ltd.).

\section{Cell culture and cells}

All cells were cultured in DMEM (Nissui Pharmaceutical Co. Ltd., Tokyo, Japan) containing 10\% fetal calf serum (Thermo Scientific, Logan, UT), $10 \mathrm{mM}$ HEPES $(7.5 \mathrm{pH}), 2 \mathrm{mM}$ L-glutamine and 100 units $/ \mathrm{ml}$ penicillin in $5 \% \mathrm{CO}_{2}$ at $37^{\circ} \mathrm{C}$. Wild type (wt) ATP7B expressing cells named $\mathrm{KB} / \mathrm{WD}$ cells were established by wt ATP7B transfection to human epidermoid carcinoma, KB-3-1 cells as described previously [5]. KB/EV cells were established from KB-3-1 cells transfected with $\mathrm{pRc} / \mathrm{CMV}$.

\section{Construction of mutant ATP7B cDNAs and transfection}

Wt ATP7B and two mutant ATP7B, Cu0 (deleted all MBS) and Cu6 (deleted the 1st-5th MBSs, MBS15) plasmids were kindly presented by Drs. Sugiyama and Terada (Akita University) $\mathrm{Cu} 0$ and $\mathrm{Cu} 6$ were constructed as described previously [37]. Another ATP7B mutant $\mathrm{M} 6 \mathrm{C} / \mathrm{S}$, the cysteines of which were replaced with serines in MBS6, was generated using site-directed mutagenesis with forward primer: 5' CCTCTGTCCACAACATAGAGTCCA $3^{\prime}$ and reverse primer: 5' AAGCGCTGGTCATCCCTGTGATTG 3'. These cDNAs were ligated into pRc/CMV (Thermo Fisher Science, Waltham, MA) and transfected into KB-3-1 cells using Lipofectamine 2000 (Thermo Fisher Science) with G418 selection as described previously [5]. Each single clone that expresses comparative amounts of ATP7B protein to that in $\mathrm{KB} / \mathrm{WD}$ cells was used in the following analysis.

To produce EGFP-wt ATP7B and EGFP-ATP7B M6C/S cDNA, BamH1-Xba1 fragments that include the entire coding region of $\mathrm{pRc} / \mathrm{CMV}$-wt ATP7B and $\mathrm{M} 6 \mathrm{C} / \mathrm{S}$ cDNA were ligated into the $B g l$ II and $X b a \mathrm{I}$ sites of pEGFP-C2 vector (Clontech, Japan). These plasmids were transiently transfected into KB-3-1 cells with Lipofectamine 2000 and observed two days after transfection.

\section{Preparation of membrane protein}

Membrane proteins were prepared as described previously [5]. Protein concentration was determined by Bio-Rad Protein Assay Kit according to the manufacturer's protocol (Bio-Rad Laboratories, Hercules, CA).

\section{Immunoblotting}

Membrane fraction protein $(100 \mu \mathrm{g})$ was subjected to $7.5 \%$ SDS-PAGE under reducing conditions. Immunoblotting was carried out as described previously [38]. A polyclonal antibody against the HA epitope (Santa Cruz Biotechnology, Santa Cruz, CA) or antiABCC4/MRP4 monoclonal antibody (M4I-10, Monsan, Netherlands) was used as a primary antibody, while horseradish peroxidase conjugated anti-rabbit or antimouse IgG (GE Healthcare, Buckinghamshire, England) was the secondary antibody respectively. Immunoreactive bands were visualized with enhanced chemiluminescence using ECL prime western blotting system (GE Healthcare).

\section{MTT assay}

Chemosensitivity was estimated by MTT colorimetric assay. We plated $3 \times 10^{3}$ cells/well of $\mathrm{KB} / \mathrm{EV}$, $\mathrm{KB} / \mathrm{Cu} 0, \mathrm{~KB} / \mathrm{Cu} 6$, and $\mathrm{KB} / \mathrm{M} 6 \mathrm{C} / \mathrm{S}$ or $5 \times 10^{3}$ cells/well of 
$\mathrm{KB} / \mathrm{WD}$ into 96-well plates and performed MTT assay as described previously [5].

\section{Subcellular distribution of doxorubicin}

We plated all cell lines at a density of $2 \times 10^{4}$ cells/well on a four-compartment glass-bottom $35-\mathrm{mm}$ dish (Greiner Bio One, Frickenhausen, Germany) and the cells were allowed to attach overnight. The cells were exposed for 1 hour to $5 \mu \mathrm{M}$ doxorubicin at $37^{\circ} \mathrm{C}$. To verify the intracellular localization of doxorubicin, cells were transfected with GFP-Golgi, RFP-Golgi, GFP-late endosome, or RFP-late endosome (Cell Light Reagents BacMam 2.0, Thermo Fisher) according to the manufacturer's protocol. Following $5 \mu \mathrm{M}$ doxorubicin exposure for 1 hour, cells were incubated in DMEM with or without $200 \mu \mathrm{M} \mathrm{BCS}, 10 \mathrm{mM} \mathrm{NH}_{4} \mathrm{Cl}$, or $10 \mu \mathrm{M}$ tamoxifen for 4 hours. All cells were stained with Hoechst 33342 (Thermo Fisher) in PBS (1:2000) for 5 minutes, washed with PBS three times, and observed using a confocal laser microscopy (Zeiss LSM700, OberKochen, Germany).

\section{Cell viability assay}

To determine the effects of $\mathrm{NH}_{4} \mathrm{Cl}$ and tamoxifen on cell viability, cells were seeded at 2000 cells/well in 96 well plates. After an overnight incubation, cells were treated with doxorubicin, SN-38 and cisplatin with or without $10 \mathrm{mM} \mathrm{NH}_{4} \mathrm{Cl}$ or $10 \mu \mathrm{M}$ tamoxifen for 24 hours. The cell viability was determined using the Cell Titer-Glo Luminescent Cell Viability Assay Kit (Promega, Madison, WI) according to the manufacturer's instructions. Luminescence was measured using Fluoroskan Ascent FL (Thermo Fisher).

\section{Statistical analysis}

Differences between groups were analyzed by twotailed Student's $t$ test. $P<0.05$ was considered significant.

\section{ACKNOWLEDGMENTS}

We appreciate Drs. Toshihiro Sugiyama and Kunihiko Terada (Akita University) for providing ATP7B cDNA and their encouragement for this work. We would like to thank Ms. Hiromi Mitsuo for her excellent technical assistance.

\section{CONFLICTS OF INTEREST}

The authors have no conflicts of interest to disclose.

\section{GRANT SUPPORT}

This work was supported in part by Grants-InAid for Science; the Platform for Drug Discovery, Informatics and Structural Life Science from the Ministry of Education, Culture, Sports, Science and Technology of Japan; the Mitsui Life Social Welfare Foundation; the Takeda Science Foundation; the Suzuken Memorial Foundation; a research grant from the Astellas Foundation for Research on Metabolic Disorders; the Kodama Memorial Fund for Medical Research; the Foundation for Promotion of Cancer Research in Japan; the Osaka Cancer Research Foundation; and the Mochida Memorial Foundation for Medical and Pharmaceutical Research.

\section{REFERENCES}

1. La Fontaine S, Ackland ML, Mercer JF. Mammalian copper-transporting P-type ATPases, ATP7A and ATP7B: emerging roles. Int J Biochem Cell Biol. 2010; 42:206-209.

2. Wang Y, Hodgkinson V, Zhu S, Weisman GA, Petris MJ. Advances in the understanding of mammalian copper transporters. Adv Nutr. 2011; 2:129-137.

3. Voskoboinik I, Camakaris J. Menkes copper-translocating P-type ATPase (ATP7A): biochemical and cell biology properties, and role in Menkes disease. J Bioenerg Biomembr. 2002; 34:363-371.

4. Bandmann O, Weiss KH, Kaler SG. Wilson's disease and other neurological copper disorders. Lancet Neurol. 2015; 14:103-113.

5. Komatsu M, Sumizawa T, Mutoh M, Chen ZS, Terada K, Furukawa T, Yang XL, Gao H, Miura N, Sugiyama $\mathrm{T}$, Akiyama S. Copper-transporting P-type adenosine triphosphatase (ATP7B) is associated with cisplatin resistance. Cancer Res. 2000; 60:1312-1316.

6. Katano K, Safaei R, Samimi G, Holzer A, Tomioka M, Goodman M, Howell SB. Confocal microscopic analysis of the interaction between cisplatin and the copper transporter ATP7B in human ovarian carcinoma cells. Clin Cancer Res. $2004 ; 10: 4578-4588$.

7. Samimi G, Katano K, Holzer AK, Safaei R, Howell SB. Modulation of the cellular pharmacology of cisplatin and its analogs by the copper exporters ATP7A and ATP7B. Mol Pharmacol. 2004; 66:25-32.

8. Miyashita H, Nitta Y, Mori S, Kanzaki A, Nakayama K, Terada K, Sugiyama T, Kawamura H, Sato A, Morikawa H, Motegi K, Takebayashi Y. Expression of coppertransporting P-type adenosine triphosphatase (ATP7B) as a chemoresistance marker in human oral squamous cell carcinoma treated with cisplatin. Oral Oncol. 2003; 39:157-162.

9. Nakayama K, Kanzaki A, Ogawa K, Miyazaki K, Neamati N, Takebayashi Y. Copper-transporting P-type 
adenosine triphosphatase (ATP7B) as a cisplatin based chemoresistance marker in ovarian carcinoma: comparative analysis with expression of MDR1, MRP1, MRP2, LRP and BCRP. Int J Cancer. 2002; 101:488-495.

10. Katano K, Kondo A, Safaei R, Holzer A, Samimi G, Mishima M, Kuo YM, Rochdi M, Howell SB. Acquisition of resistance to cisplatin is accompanied by changes in the cellular pharmacology of copper. Cancer Res. 2002; 62:6559-6565.

11. Owatari S, Akune S, Komatsu M, Ikeda R, Firth SD, Che XF, Yamamoto M, Tsujikawa K, Kitazono M, Ishizawa T, Takeuchi T, Aikou T, Mercer JF, Akiyama S, Furukawa T. Copper-transporting P-type ATPase, ATP7A, confers multidrug resistance and its expression is related to resistance to SN-38 in clinical colon cancer. Cancer Res. 2007; 67:4860-4868.

12. Gottesman MM, Fojo T, Bates SE. Multidrug resistance in cancer: role of ATP-dependent transporters. Nat Rev Cancer. 2002; 2:48-58.

13. Kunjachan S, Rychlik B, Storm G, Kiessling F, Lammers T. Multidrug resistance: Physiological principles and nanomedical solutions. Adv Drug Deliv Rev. 2013; 65:1852-1865.

14. Fojo T, Bates S. Strategies for reversing drug resistance. Oncogene. 2003; 22:7512-7523.

15. Shaffer BC, Gillet JP, Patel C, Baer MR, Bates SE, Gottesman MM. Drug resistance: still a daunting challenge to the successful treatment of AML. Drug Resist Updat. 2012; 15:62-69.

16. Safaei R, Adams PL, Mathews RA, Manorek G, Howell $\mathrm{SB}$. The role of metal binding and phosphorylation domains in the regulation of cisplatin-induced trafficking of ATP7B. Metallomics. 2013; 5:964-972.

17. Payne AS, Kelly EJ, Gitlin JD. Functional expression of the Wilson disease protein reveals mislocalization and impaired copper-dependent trafficking of the common H1069Q mutation. Proc Natl Acad Sci U S A. 1998; 95:10854-10859.

18. Polishchuk EV, Concilli M, Iacobacci S, Chesi G, Pastore N, Piccolo P, Paladino S, Baldantoni D, van ISC, Chan J, Chang CJ, Amoresano A, Pane F, Pucci P, Tarallo A, Parenti $G$, et al. Wilson disease protein ATP7B utilizes lysosomal exocytosis to maintain copper homeostasis. Dev Cell. 2014; 29:686-700.

19. Safaei R, Adams PL, Maktabi MH, Mathews RA, Howell $\mathrm{SB}$. The CXXC motifs in the metal binding domains are required for ATP7B to mediate resistance to cisplatin. J Inorg Biochem. 2012; 110:8-17.

20. Ohkuma S, Poole B. Fluorescence probe measurement of the intralysosomal $\mathrm{pH}$ in living cells and the perturbation of $\mathrm{pH}$ by various agents. Proc Natl Acad Sci U S A. 1978; 75:3327-3331.
21. Altan N, Chen Y, Schindler M, Simon SM. Tamoxifen inhibits acidification in cells independent of the estrogen receptor. Proc Natl Acad Sci U S A. 1999; 96: 4432-4437.

22. Safaei R, Katano K, Larson BJ, Samimi G, Holzer AK, Naerdemann W, Tomioka M, Goodman M, Howell SB. Intracellular localization and trafficking of fluoresceinlabeled cisplatin in human ovarian carcinoma cells. Clin Cancer Res. 2005; 11:756-767.

23. Cater MA, Forbes J, La Fontaine S, Cox D, Mercer JF. Intracellular trafficking of the human Wilson protein: the role of the six N-terminal metal-binding sites. Biochem J. 2004; 380:805-813.

24. Safaei R, Otani S, Larson BJ, Rasmussen ML, Howell SB. Transport of cisplatin by the copper efflux transporter ATP7B. Mol Pharmacol. 2008; 73:461-468.

25. Walker JM, Huster D, Ralle M, Morgan CT, Blackburn NJ, Lutsenko S. The N-terminal metal-binding site 2 of the Wilson's Disease Protein plays a key role in the transfer of copper from Atox1. J Biol Chem. 2004; 279:15376-15384.

26. Dolgova NV, Nokhrin S, Yu CH, George GN, Dmitriev OY. Copper chaperone Atox 1 interacts with the metalbinding domain of Wilson's disease protein in cisplatin detoxification. Biochem J. 2013; 454:147-156.

27. Larin D, Mekios C, Das K, Ross B, Yang AS, Gilliam TC. Characterization of the interaction between the Wilson and Menkes disease proteins and the cytoplasmic copper chaperone, HAH1p. J Biol Chem. 1999; 274:28497-28504.

28. Dolgova NV, Olson D, Lutsenko S, Dmitriev OY. The soluble metal-binding domain of the copper transporter ATP7B binds and detoxifies cisplatin. Biochem J. 2009; 419:51-56, $53 \mathrm{p}$ following 56.

29. Tadini-Buoninsegni F, Bartolommei G, Moncelli MR, Inesi G, Galliani A, Sinisi M, Losacco M, Natile G, Arnesano F. Translocation of platinum anticancer drugs by human copper ATPases ATP7A and ATP7B. Angew Chem Int Ed Engl. 2014; 53:1297-1301.

30. Duvvuri M, Krise JP. Intracellular drug sequestration events associated with the emergence of multidrug resistance: a mechanistic review. Front Biosci. 2005; 10:1499-1509.

31. Furukawa T, Komatsu M, Ikeda R, Tsujikawa K, Akiyama $\mathrm{S}$. Copper transport systems are involved in multidrug resistance and drug transport. Curr Med Chem. 2008; 15:3268-3278.

32. Rajagopal A, Simon SM. Subcellular localization and activity of multidrug resistance proteins. Mol Biol Cell. 2003; 14:3389-3399.

33. Altan N, Chen Y, Schindler M, Simon SM. Defective acidification in human breast tumor cells and implications for chemotherapy. J Exp Med. 1998; 187:1583-1598. 
34. Nakayama K, Kanzaki A, Terada K, Mutoh M, Ogawa K, Sugiyama T, Takenoshita S, Itoh K, Yaegashi N, Miyazaki K, Neamati N, Takebayashi Y. Prognostic value of the $\mathrm{Cu}$-transporting ATPase in ovarian carcinoma patients receiving cisplatin-based chemotherapy. Clin Cancer Res. 2004; 10:2804-2811.

35. Ohbu M, Ogawa K, Konno S, Kanzaki A, Terada K, Sugiyama T, Takebayashi Y. Copper-transporting P-type adenosine triphosphatase (ATP7B) is expressed in human gastric carcinoma. Cancer Lett. 2003; 189:33-38.

36. Kanzaki A, Toi M, Neamati N, Miyashita H, Oubu M, Nakayama K, Bando H, Ogawa K, Mutoh M, Mori S, Terada K, Sugiyama T, Fukumoto M, Takebayashi Y.
Copper-transporting P-type adenosine triphosphatase (ATP7B) is expressed in human breast carcinoma. Jpn J Cancer Res. 2002; 93:70-77.

37. Iida M, Terada K, Sambongi Y, Wakabayashi T, Miura N, Koyama K, Futai M, Sugiyama T. Analysis of functional domains of Wilson disease protein (ATP7B) in Saccharomyces cerevisiae. FEBS Lett. 1998; 428:281-285.

38. Shinsato Y, Furukawa T, Yunoue S, Yonezawa H, Minami K, Nishizawa Y, Ikeda R, Kawahara K, Yamamoto M, Hirano H, Tokimura H, Arita K. Reduction of MLH1 and PMS2 confers temozolomide resistance and is associated with recurrence of glioblastoma. Oncotarget. 2013; 4:22612270. doi:10.18632/oncotarget.1302. 